zou zijjn, dat elke donateur zelt' of dovr een gensachtigde zich zou kummen overtuigen of zijn gift in de kas is verantwoord.

Afgezien van de daartegen aantevoeren nadeelen, zooals de kosten daaraan verbonden en de ongewenschte publiciteit, beveelt schrijver daarom aan of een gedetailleerde lijst van giften te hechten aan het accountantsrapport, dan wel deponcering van een dergelijke lijst bij ecn in te stellen centraal informatiebureau, ten gerieve van donateurs van liefdadigheidsinstellingen.

Ook al zal het publick weinig van dit contrôlemiddel gebruik maken, de preventieve werking ervan is toch van waarde, terwijl de kosten in verhouding tot het geheel niet zoo groot zullen zijn. Tegenover het gevende publiek is deze publicatie ecn imperaticve verplichting.

Teneinde geen noodelooze gelegenheid tot fraudeering te geven, moet bovendien het publiek er o.a. steeds op gewezen worden :

$1^{\circ}$. nooit contant te geven, maar steeds per cheque (of giro) te betalen ;

$2^{\circ}$. cheques nooit betalbaar te stellen aan penningmeester of andere personen, maar steeds aan de instelling zelve;

Hieraan zouden wij willen toevoegen:

$3^{\circ}$. indien publicatie der giften wordt toegepast, nooit zijn gift te laten vermelden onder de letters $\mathrm{X}$ of N.N. of onder cen algemeen motto.

De accountants moeten daamaast meer aandacht besteden aan hun verklaringen, waarvoor schrijver een standaard als minimum zou willen vaststellen.

Zij moeten aandringen op bovenbedoelde publicatielijst van ontvangsten en nagaan of het totaal dezer lijst overeenkomt met het totaal per kas verantwoord.

Eventueel zouden zij kunnen bewerken, den datum van afsluiting bij de instellingen zoo te kiezen, dat de door het accountantskantoor te verrichten werkzaamheden niet samenvallen met den drukken tijd der accountants.

Deze datum kan samenvallen met den besten tijd voor het bestuur van een liefdadigheidsinstelling n.m.l. na de zomer- of wintercampagne bịv. 31 October of $30 \mathrm{April}$.

L. A. B.

\section{REPERTORIUM VAN TIJDSCHRIFT-LITERATUUR OP HET GEBIED VAN ACCOUNTANCY EN BEDRIJFSHUISHOUDKUNDE}

Redactie: Mej. Dr. R. PHILIPS en Drs. G. L. GROFNEVELD voor bedrijfseconomie en J. P. DE HAAN en

J. C. SPANGENBERG voor accountancy

(De Systematiek, welke in dit repertorium wordt gevolgd, is uiteengezet in het nummer van Januari 1929 van dit blad)

\section{A. ACCOUNTANCY}

\section{HET ACCOUNTANTSBEROEP}

The accounts of executorships and will-trusts

Cr ave n s, G. - Het is gewenscht dat steeds accountants benoemd worden voor het inrichten en nazien van de rekening en verantwoording van den executeur testamentair.

A II I (A 33)

The Inc. Accountants' Journal Mei 1929

$\geqslant$ The future of the accountancy profession

Spicer, E. E. - Wettelijke regeling van het accountantsberoep is onafwendbaar, indien de "Average Standard" vermindert. Schrijver adviseert verhooging van de "Average Standard", uitbreiding der werkzaamheden van den accountant zooals voorlichting bij samenstelling van testamenten -- vennootschapscontracten - successierechtei - trustvorming etc. Het afleggen van mondelinge verklaringen up aandeelhouders vergaderingen is gewenscht. Specialisatie van den accountantsarbeid met als gevolg vorming van groote accountantsfirma's is te verwachten.

A 114 (A 33)

The Inc. Accountants' Journal Mei 1929

Samenwerking tusschen public accountant en accountant der Directe Belastingen

A. N. - Beschreven wordt dat de taak van den accountant der Directe Belastingen een geheel andere is dan van den public-accountant en hoe ook de wettelijke regeling van het accountantsberoep dienstgemaakt kan worden aan de samenwerking tusschen den accountant der belastingen en den public-accountant.

A II 4 (A 33)

Maandblad loor Accountancy en Bedrijfshuishoudkunde Juli 1929

\section{LEER VAN DE INRICHTING}

Beschrijving van de administratie der afdeeling „Kapitaalverzekering" van de N.V. "Noord-Braband", Maatschappij van verzekering op het leven te Waalwijk

$\mathrm{H}$ u y s m a n s, H. - Slot van een serie artikelen over bovenvermeld onderwerp, waarin de debiteurenadministratie verder wordt uitgewerkt en een schematisch overzicht wordt gegeven van de Administratie

A III 3 (A 25) Administratieve Arbeid Mei 1929

\section{Kostprijsberekening voor auto-tractie}

K r u u k, F. - Schr. geeft een overzicht van de bij den Reinigingsdienst te 's-Gravenhage gevoerde kostprijsadministratie.

A III 3 (A 25)

De Gemeentefinanciën van 27 Juli 1929

Het intacthouden van het bedrijfskapitaal van een gemeentelijk bedrijf

N. d e K. - Uiteengezet wordt hoe en door het gebruik van welke rekeninghoofden in het grootboek steeds kan worden gezien hoe de kapitaalsverhouding is tusschen het gemeentebedrijf en de Gemeente. A III 3 (A 25) Accountancy Juli 1929

\section{LEER VAN DE CONTROLE}

\section{De Accountant en het beheer}

Otte, C. J. B. - Behandeld wordt of de accountant zich al dan niet met het beheer moet inlaten. Schrijver komt tot de conclusie, dat dit wel het geval is.

A IV 2 (A 33)

Accountancy Juli 1929

De verantwoordelijkheid van den gemeente-accountant

L (e p pink, J. A.) - Van den accountant mag niet worden verlangd, dat hij controle uitoefent op de wijze, waarop de technische controleerende ambtenaren hun taak vervullen.

A IV 2 (A 33) Financieel Overheidsbeheer yan 15 Juli 1929

Uit de linancieele huishouding der overheid

T e x t o r, J. H. - Naar aanleiding van de voorgestelde wijzigingen in de Genseentewet wordt een beschouwing gegeven van de controle op de Gemeente Financien.

A IV 3 (A 33)

Maandblad voor Accountancy en Bedrïfshuishoudkunde Juli 1929

\section{B. BEDRIJFSHUISHOUDKUNDE}

\section{a. ALGEMEENE BEDRIJFSHUISHOUDKUNDE}

\section{LEER VAN DEN KOSTPRIJS EN DE PRIJSVORMING}

Kosten van wegverbreedingen

L u u r ing, B. B. -.. De te maken kosten worden in vier groepen onderverdeeld. Hiertegenover staan de ontvangsten, welke men mag verwachten. In de praktijk blijft de nacalculatie meestal achterwege. Schr. tracht voor deze fout bij de behandeling van de financieele resultaten van wegverbreedingen een oplossing te vinden, geeft een opzet van de berekening der werkelijke kosten en een vergelijkend overzicht van de lasten en baten volgens begrooting en opzet der kosten; buitendien een staatje van begrooting der kosten van verbreeding.

B a IV 2b (A 24)

Technisch Gemeenteblad Juli 1929

\section{Het ontstaan van het inkomen der onderneming}

H (u y s m a n), Dr. C. - - Schr, geeft een weergave van de meeningen over dit onderwerp in de algemeene economie.

B a IV 8 (A 1$)$ 


\section{L.EER VAN DE FINANCIERING}

De voorziening in de kapitaalbehoefte der indıstrie door of door bemiddeling van banken

Fentener van Vlissingen, F. H. -- Bij voortgaande ontwikkeling der industrie tot grooter bedrijfseenhedell en de steeds stijgende kapitaalbehoefte per productie-eenheid, moet de voorziening daarvan steeds meer door of door bemiddeling van banken geschieden, um op zoo gunstig mogelijke voorwaarden voldoende kapitaal te verkrijgen en om het risico voor de geldgevers zoo gering mogelijk te maken. Wil een zoodanige samenwerking een zoo groot mogelijk nuttig effect afwerpen, dan moeten de desbetreffende wetten aangepast worden aan de praktijk en de kapitaalverschaffing geschieden op economischen grondslag. De conclusie hieruit voor Nederland is de oprichting van een gezamenlijke Industriebank en de rechtelijke erkenning van het geven van zekerheid op roerende gocderen, welke de debiteur onder zich houdt.

B a V 1 (A 2)

De Ingenieur 13 Juli 1929

\section{De belastbaarheid van claims}

$\mathrm{N}$ ij st, J. J. M. H. - Het toenemend gebruik van claims is mede verbonden aan fiscale voordeelen. Zoo is de claim vrijgesteld van de Rijks Inkomstenbelasting. De onjuistheid hiervan wordt uitvoerig gemotiveerd. Het baant den weg voor expansieve maatschappijen, iedere hetaling van Rijks Inkomstenbelasting te ontgaan. De clain brengt ook een viijstelling van de dividencl- en tantiemebelasting.

$\mathrm{B}$ a V 3a (A 2)

Weekblad voor Privaotrecht. Notarisambt en Registratie van 4, 11 en? $18 \mathrm{Mei} 1920$

\section{Het koopen op afbetaling}

T e ke n b r o ek, Dr. E. - Schr. verklaart het afbetalingsstelsel uit den drang naar vergrooting van den afzet eenerzijds, uit andere levenshouding anderzijds. De gezonde en levensvatbare kern ligt bij het duurzame verbruiksgoed, waar het een element van sparen kan bevatten. Het systeen vergroot hier de kans op overproductie.

$B$ a $V 5$ c (A 2)

Vragen des Tijds van Juli-Aug. 1929

\section{LEER VAN DE, ORGANISATIE}

\section{Zijn er te veel winkels?}

To b i, Dr. E. J. - Schr. erkent, dat het door hem verzamelde feitenmateriaal niet absoluut nauwkeurig is. Een breed opgezet onderzoek naar juiste cijfers is gewenscht. Van een "te-veel” kan zoowel prijsverhooging als prijsverlaging het gevolg zijn.

B a VI 9 (A I)

De Naamlooze Vennootschap van Juli 1929

\section{Collectieve propaganda en reclame voor electriciteit}

Moorma n, J. - Propaganda en reclame in het algemeen, de collectieve propaganda, de electriciteitspropaganda in het buitenland en de taak in ons land zijn de punten van behandeling.

B a VI 11 (A 20)

Electrotechniek 10 Juli 1929

\section{Industrial Organisation}

SI o a n, K. M. - Otiderwetsch zijn beteekent inefficiency. Waste in grondstoffenverbruik-tijd en energie moeten worden geëlimineerd. Schrijver bespreekt de grondslagen en geeft een beschrijving van de wetenschappelijke bedrijfsorganisatie van een fabrieksbedrijf

B a VI 13 (A 12)

The Accountants' Magazine Mei 192?

\section{Les systemes et l'organisation}

R a visse, G. - De organisator moet voor alles grondig vertrouwd zijn met de systemathiek der organisatie en moet de bedrijfsleiders ervan overtuigen, dat voor hen de administratieve functie primair is en de vakkennis secundair in tegenstelling met de afdeelingschefs, voor wie de vakkennis primair is.

B a VI 13 (A 12)

Mon Bureatl Mei 1920

Surveillance du mouvement des marchandises dans le commerce de détail

Billa rd, Ch. - Beschrijving van een soort planbord in een kleedingmagazijn, waardoor het mogelijk is een overzicht te verkrijgeı over de samenstelling en hoeveellheden der aanwczige stoffen, costuums ctc. Dit planbord kan dan als basis dienen voor de aankoopen van stoffen en fabricatie der costuums.

B a VI 19 (A 12)

Mon Bureau Mei 1929

\section{L'organisation de la vente et la documentation économique}

Thum en, Ch. B. - De wetenschappelijke organisatie van den verkoop omvat de le. de studie van de markt. 2e. de studie der conjuctuur. 3e. de samenstelling van verkoopquota's.
Dit vereischt veel werk op het gebied der documentatie en registraiie. Schrijver geeft "en overzicht van de "documentation économique" in Anterika, Europa en Frankrijk in 't bijzonder. B a VI 21 (A 18)

Mon Bureau Mei 1929

\section{Amerika V}

(iersten ber $g, K$. - De reclame in Amerika wordt zorgvuldig voorbereid en geschiedt in overleg met de afdeeling verkoop.

Schrijver wijst verder op de systemathiek in de leiding der onderneming en het werken van de leiders meer voor de toekomst dan voor het huidige productieproces

B a VI 21 (A 18)

Administratieve Arbeid Mei 1929

L'Organisation du service de la registrature dans une grande administration publique

Millon, P. - Schrijver breekt een lans voor het dossierstelsel en geeft een uitvoerige beschrijving van de organisatie van het archief hij de Posterijen in Duitschland (decimaal stelsel).

B a $\mathrm{VI}^{\circ} 23(\mathrm{~A} 34)$

Mon Bureau Mei 1929

\section{Documentatie van tijdschriften}

W e ber, E. P. - Voor de documentatie van den inhoud van tijdschriften alsmede voor het opbergen, bestaan verschillende methoden. Schrijver beschrijft de meest gangbare.

B a VI 23 (A 34)

Administratieve Arbeid Mei 1929

\section{LEER VAN DE ARBEIDSVOORWAARDEN}

\section{Loonstelsels III. De mérites}

Groot, Drs. A. M. - Vergelijking van Halsey en Rowanstelsel. De stelsels van Gantt en Taylor zijn slechts toepashaar bij goed georganiseerde en gestandaardiseerde productie.

B a VII 3 (A 14) De Naamlooze Vennootschap Juli 1929

Psychotechniek der behandeling van kantoorpersoneel

Gi es e, Prof. Dr. F. - De rationalisatie van den kantoorarbeid stuit dikwerf op het lijdelijk verzet van den zich hooger voelenden kantoorarbeider. Daarom is de reorganisatie op kantoorarbeid meer een vraagstuk van sociologische analyse en psychologische arbeidsvoorbereiding. welke laatste vraagstukken schrijver eenigszins uitvoeriger behandelt.

B a VII 5 (A 7)

Administratieve Arbeid Mei 1929

\section{b. BIJZONDERE BEDRIJVEN}

\section{LANDBOUW- EN CULTUURBEDRIJVEN}

\section{De vermeerdering van den cultuurgrond in Nederland}

$V$ an $P$ a n h u y s, Jhr. Ir. E. E. W. - Het gebrek aan grond in Nederland leidt tot het vraagstuk van vermeerdering van den cultuurgrond, welk vraagstuk hier economisch, administratief en technisch beschouwd wordt. Tenslotte wordt de winning van cultuurgrond als vorm van werkverschaffing behandeld.

B b IV 1 (B I)

De Ingenieur p. A 216-A 232 (1929)

\section{INDUSTRIE}

\section{Maschinenindustrie and Eisengiesserei in Holland}

D r e s d e n, Prof. Ir. D. -- Ontwikkelingsmogelijkheden werden de machine-industrie geboden door scheepvaart, polderbemaling en textielindustrie. Onze vrijhandelspolitiek vergemakkelijkte samenwerking met buitenlandsche en binnenlandsche fabrieken. We constateeren een aanzienlijke stijging van de bedragen, die per arbeider in vaste productiemiddelen worden geïnvesteerd. De inheemsche markt is het voornaamste afzetgebied van vele fabrieken; bovendien heeft Ned. Indië een groote beteekenis. Vele speciale producten hebben eer belangrijke plaats op de wereldmarkt veroverd.

B b V 3 (B 3c)

Finanzwirtschaftliche Uebersicht der statistischen Abteilung der Amsterdamsche Bank Juli 1929

\section{Collectieve propaganda en reclame voor electriciteit}

Mo orm a n, J. -- Propaganda en reclame in het algemeen, de collectieve propaganda in het bijzonder, de electriciteitspropaganda in het buitenland en de taak in ons land zijn de punten van behandeling. B h V 19 (B 3r) 
De electriciteitspropaganda in de Vereenigde Staten en het nut van een leiddraad voor den omvang van electrische huisinstallaties

H albertsma, Dr. Ir. N. A. - In Amerika nadert men het verzadigingspunt van de electrificatie voorzoover zij in de breedte gaat. Daarom zoekt men het in de diepte: vermeerdering van stroomverbruik door electriciteitspropaganda.

B b V 19 (B 3r)

De Ingenieur 10 Juli 1929

\section{VRAGENBUS}

Vragen omtrent onderwerpen, die voor den accountant in de uitoefening van zijn beroep van belang kunnen zïn, kunnen worden ingezonden bij den Secretaris van de Redactie.

De Redactie is bereid, om de grenzen, waarbinnen de vragen, die voor beantwoording in aanmerking komen, zoo ruim nogelijk te stellen, zoodat zoowel die van juridischen, als die van bedrijfshuishoudkundigen aard daar binnen vallen, mits de vragen slechts blijven binnen het gebied, dat het blad dienen wil.

De beantwoording geschiedt door één der medewerkers of redactieleden individueel, zoodat de antwoorden niet mogen worden geacht steeds de meening der Redactie in haar geheel weer te geven.

\section{Vraag No. 16}

Naar ik meen, is het Wetsontwerp Ruys 1913 tot wijziging van de Gemeentewet, gewijzigd opnieuw ingediend in $1928 \mathrm{door}$ Minister Kan. Is dit angenomen, dus wet geworden?

\section{Antwoord}

Uet wetsontwerI, "Rian" tot herziening van de Gemeentewet, dat op vele punten belangrijk afwijkt van het vorige ontwerp "Ruys", - zie de rubriek: „Uit de financieele huishouding der overheid" Juli 1929 -, is nog niet tot wet verheven. Dat dit zal geschieden, is nog niet heel zeker.

J. H. T.

\section{Vraag No. 17}

Is het wetsontwerp tot wijziging van de financiecle verhouding tusschen het Rijk en de Gemrenten aangenomen, of is dit nog in behandeling?

\section{Antwoord}

Het wetsontwerp tot wijziging van de financieele verhouding tusschen het Rijk en de Gemeenten is aangenomen. Het is de wet van 15 Juli 1929. (Stbl. No. 388) Bij Koninklijk Besluit ran 4 November 1929 zijn voorschriften gegeven tot uitvoering der wet (Stbl. 476).

J. 11. T.

\section{NIEUWE BOEKEN}

\section{A. Bedrijfshuishoudkunde}

Aschenbrenner, R. Exporthandel und direkter Industrielixport in der Nachkriegszeit. Berlin, 1929.

Aymar, G. C. Introduction to advertising illustration. NewYork, 1929.

Baldwin, W. II. Shopping book. New-York, 1929.

Bolte, $F$. Dic kurzfristige Wrfolgsrechnung im Bergbau unter besond. Berücksichtigung des Steinkohlenbergbaues. Berlin, 1929.

Burtt, H. E. Psychology and industrial efficiency. New-York, 1929.

Business Administration, Practical. American technical Soc. Chicago, 1929.

Casey, C. C. Way to more productive selling. New-York, 1929. ('omish, N. II. Coopcrative marketing of agricultural pro iucts. New-York, 1929.

Dartnell Corporation. Independent retailing. C'hicago, 1929.

Doerr, A., II. Ohlig. und 'I'. Meyer. Ginzelhandelsbetriebskinnde für Verkäufer- und Verkäuferimnenklassen und Finzelh:undelsfachschulen. Jeipzig, 1929.

Dominile, II. Das Schaltwerk. Fabrikhochhaus und Hallenban der Siemens-Schurkertwerke A. G. Berlin, 1929.

I'alk, K. Kostenberechnung im Baugewerbe. München, 1929.

F'indler, $h$, Das Hollerith- Lochkarten- Verfahren fül nuaschinelle Buchlaltung und Statistik. Berlin, 1929.

Gade, G. A. Hand-to-mouth buying and the inventory situation. Landslowne, 1929.

Goode, $K$. M. Inow to turn people into gold. F'oleword by i. St. limo Lewis. New-York, 1929.

IIandbuch der internationalen Kunstseide-Industrie. IIrsg, von L. und J. Mossner. Jhrg. I. Berlin, 1.929.

IIailrk, i. Ch. Arbeitszeit-problem und Industrickostenwirtschaft (Theorie der optimal wirtschaftlichen Betricbszeit). Berlin, 1929.

IIecht, W. Jer Zement-Kartellpreis. Leipzig, 1929.

Iloffmann, R. Metallstock und Wirtschaftlichkeit. Ein Beitrag zur Frage der Verzinsungskosten auf Hüttenwerken. Halle (Saale), 1929.

Iloopinggarner; N. L. Personality and business ability analysis. New-York, 1929.

II undhausen, C. Kundenwerbung amerikanischer Banken. Berlin, 1929.

Jordan. J. P. Controller, his functions, activities and relationships with the line organization and other specialized departments. New-York, 1929.

Kilgus, E. Kapitalanlage-Gesellschaften. Investment 'l'usts. Berline, 1929.

Killough, $I$. B. and $L$. W. Killough. Raw materials of industrialism. New-York, 1929.

Lalande. Ch. I'organisation des approvisionnements dans l'industrie. Achats et magasins. Paris, 1929.

Lauterer, $\boldsymbol{h}$. Die Reklame von morgen. Frankfurt a. M., 1929. Lentz, W. Die Verküuferin. Freiberg i. Sa., 1929.

Lodegast, K. Winanzmathematik. Ein Ijeitfaden für dic Praxis ins besondere für Kommunen, Banken und Sparkassen. Berlin, 1929.

Longnecker, $J$. W. Selling insurance by cooperative advęrtising. New-Yolk, 1929.

Luduig, II. Konjunkturbeobachtung und Marktananlyse als Grundlagen des Verkaufsbudjets einer Automobilfabrik. Berlin-Charlotteuburg, 1929.

Mc. Nicce, T. M. Measurement and control of selling and distribution costs. New-York, 1929.

Moser, W. E. Hectrical utilities. The Crisis in public control. New-York, 1929.

Petcr, $G$. Wirtschaftsf ragen der deutschen Hohlglasindustrie. (Yobutg, 1929.

Phelps, G. H. ()ur biggest customer. New-York, 1929.

l’öschl, V. Verkaufsschule und Verkaufslchrer. Berlin, 1929.

Raschenberger, $\boldsymbol{H}$. Internationales Revisions- und Treuhandwesen. Wien, 1929.

Reitell, C. Humanizing cost findings. New-York, 1929.

Reithinger, A. Statistischer Quellen-Nachweis für die Durchfühıung von Marktanalysen. Berlin, 1929.

Renard, C. A. Allocation of selling and administrative expen. ses to units sold. New-York, 1929.

Roth, II. Die Ưbererzeugung in der. Welthandelsware Kaffe im Keitraum von 1790-1929. Jena, 1929.

S'ecrist, $H$. Widening retail market and consumers' buying habits. New-York, 1929.

Stopp, C. Die deutsche Kartonpapierindustrie. Leipzig, 1929 Surey, R. Iayout technique in advertising. New-York, 1929. 